\title{
Different Doses of the Enhanced UV-B Radiation Effects on Wheat Somatic Cell Division
}

\author{
Feifeng Liu', ${ }^{1,}$ Huize Chen ${ }^{1,2}$, Rong Han ${ }^{1,2 *}$ \\ ${ }^{1}$ College of Life Science, Shanxi Normal University, Linfen, China \\ ${ }^{2}$ Higher Education Key Laboratory of Plant Molecular and Environmental Stress Response (Shanxi Normal \\ University) in Shanxi Province, Linfen, China \\ Email: "hhwrsl@163.com
}

Received 25 May 2015; accepted 27 June 2015; published 30 June 2015

Copyright (C) 2015 by authors and Scientific Research Publishing Inc.

This work is licensed under the Creative Commons Attribution International License (CC BY). http://creativecommons.org/licenses/by/4.0/

C) (†) Open Access

\section{Abstract}

Being sessile, plants are continuously exposed to DNA-damaging agents presenting in the environment such as ultraviolet (UV). Sunlight acts as an energy source for photosynthetic plants; hence, avoidance of UV radiations (namely, UV-A, 315 - $400 \mathrm{~nm}$; UV-B, 280 - $315 \mathrm{~nm}$; and UV-C, $<280 \mathbf{n m}$ ) is unpreventable. DNA in particular strongly absorbs UV-B; therefore, it is the most important target for UV-B induced damages. This paper mainly used different doses of the enhanced UV-B radiation (B $B_{1}$ group: $4.05 \mathrm{~kJ} \cdot \mathrm{m}^{-2} \cdot \mathrm{d}^{-1}, B_{2}$ group: $10.08 \mathrm{~kJ} \cdot \mathrm{m}^{-2} \cdot \mathrm{d}^{-1}, B_{3}$ group: $7.05 \mathrm{~kJ} \cdot \mathrm{m}^{-2 \cdot} \cdot \mathrm{d}^{-1}, B_{4}$ group: $23.02 \mathrm{~kJ} \cdot \mathrm{m}^{-2} \cdot \mathrm{d}^{-1}$ ) treatment wheat, then, explored on the growth of wheat root and wheat root tip cell of chromosome aberration effect. In wheat, root-tip cells were observed with confocal laser scanning microscopy (CLSM), the results showed that low doses of $B_{1}$ group $\left(4.05 \mathrm{~kJ} \cdot \mathrm{m}^{-2} \cdot \mathrm{d}^{-1}\right)$ promoted the growth of wheat root and cell mitosis frequency. But high dose of $B_{2}$ group $(10.08$ $\left.\mathrm{kJ} \cdot \mathrm{m}^{-2} \cdot \mathrm{d}^{-1}\right), B_{3}$ group $\left(17.05 \mathrm{~kJ} \cdot \mathrm{m}^{-2} \cdot \mathrm{d}^{-1}\right), B_{4}$ group $\left(23.02 \mathrm{~kJ} \cdot \mathrm{m}^{-2} \cdot \mathrm{d}^{-1}\right)$ inhibited the growth of wheat root tip, and made crooked growth of wheat root, and inhibited the wheat root tip cell mitotic frequency and processed that induce root tip cells of wheat produce all kinds of aberration of chromosome in the interphase containing "multiple nucleoli nuclei", "incomplete nuclei", "long round nuclei", "bean sprouts nucleus". In mitosis M period contains "dissociative chromosome", "chromosome bridge", "adhesion chromosome", "multi-bundle divide", "nuclear anomalies". After, high doses of enhanced UV-B radiation treatment, most of the cell cycle anomaly concentrated in mitosis interphase. In mitosis M period, with UV-B radiation dose enhanced chromosome aberration rate was on the rise and the aberration types also increasing.

\section{Keywords}

Wheat, Enhanced UV-B Radiation, Chromosome Aberration, Confocal Laser Scanning Microscopy (CLSM)

"Corresponding author. 


\section{Introduction}

Wheat is one of the earliest soil cultivation crops, which is widely distributed in the world; it also provides for a basic food for people globally [1]. Plants as sessile organisms that require sunlight to grow and develop, are inevitably exposed to ultraviolet (UV) wavelengths (200 - $400 \mathrm{~nm}$ ), which represent almost $7 \%$ of the electromagnetic radiation emitted from the sun [2]. Sunlight contains energy rich UV-A (320 - $400 \mathrm{~nm})$, UV-B (290 $320 \mathrm{~nm})$, and UV-C (280 - $100 \mathrm{~nm})$ light. UV-B light (280 - $315 \mathrm{~nm})$ is a natural component of sunlight, and due to its short wavelength, it has the highest energy of the sunlight spectrum at the Earth's surface [3]. Low fluence UV-B light promotes photomorphogenesis, and induces the transcription of genes involved in flavonoid synthesis [4]. While high-intensity UV-B light causes damage to DNA, protein, and other macromolecules [3]. The UV-B radiation on the ground would increase by 20\% - 40\% during 2010-2020 through the GISS model [5]. GISS modelling has suggested that there is a springtime enhancement of erythemal UV-B doses of up to $14 \%$ in the Northern Hemisphere and $40 \%$ in the Southern Hemisphere. Even a small increase in incident UV-B radiation can have significant biological effects [6]. UV-B radiation influences the ecosystem and various organisms [7]. Hence, it is important to study how crops protect themselves against the potentially damaging effects of UV-B.

The plant cell differs from the animal one by the absence of the centriole. Besides, the spindle pole in the plant cell is much broader than in the animal cell [8]. Briefly, the prototypical mitotic cycle consists of a DNA replication phase (S-phase), and a chromosome condensation and sister chromatid segregation phase (M-phase), which are preceded by G1 and G2 gap phases, respectively. Typically, this cell cycle is associated with cell division, and M-phase is generally coupled to karyokinesis and cytokinesis, which generate daughter cells with chromosome number and nuclear DNA content identical to those of their mother cell [9]. Precise cell division with transmission of genetic information is a key process controlling growth and development in all eukaryotic organisms [10]. Chromosomes need to be properly replicated and condensed then attached to the spindle fibers in order to be distributed evenly among daughter cells [11].

In recent years, a large number of scientific researches show that the enhanced UV-B radiation not only inhibits the growth of wheat, corn and other crops [12], changes its absorption of mineral nutrition [13] promoting the increase of enzyme activity, [14] leads to the destruction of the membrane structure, [15] [16] produces the phenomenon such as micronucleus and chromosome aberration [17] and that preliminary work of our group found that enhanced UV-B could inhibit the cell mitosis frequency of wheat and cause chromosome aberration. The phenomenon of "partition-bundle division" is one of the aberration types. "Partition-bundle division" is also called "multiple bundle division".

We did detailed and systemic study on the different doses of the enhanced UV-B radiation damage to the wheat root tip cells. Then, wheat root tip cells were observed with confocal laser scanning microscopy (CLSM). By observing different doses of UV-B radiation anomaly of mitosis, this research enriches the basic mechanism of plant mitosis, and helps us to find the possible mechanism of wheat defense against UV-B to guide the production of wheat in the future.

\section{Materials and Methods}

\subsection{Plant Materials}

“ML7113” (Triticum aestivum) was supplied by wheat Research Institute of Shanxi Academy of Agricultural Sciences. The wheat seeds of fully germination and uniform size were selected, and sterilized for 10 min with $1 \%$ $\mathrm{NaClO}$, and then were washed for 10 min with running water, and then cultured in Petri dishes with 30 seeds per dish, and each group of repeated three times at $25^{\circ} \mathrm{C}$ and $60 \%$ relative humidity under a $8 \mathrm{~h} / 16 \mathrm{~h}$ light/dark regime for 7 days [18].

\subsection{UV-B Radiation Treatment}

Five groups were used in the experiment: four groups were treated with different doses of the enhanced UV-B for 8 h every day, and one control group was treated without UV-B. Processing of the method is shown in the Table 1. Enhanced UV-B radiation was provided by filtered Qin brand (Baoji Lamp Factory, China). The lamps (30 W, $297 \mathrm{~nm}$ ) were suspended above and perpendicular to the dishes; the intensity was controlled through the distance between the lamp and the dishes [19]. The dosage was respectively $\mathrm{B}_{1}$ group: $4.05 \mathrm{~kJ} \cdot \mathrm{m}^{-2} \cdot \mathrm{d}^{-1} ; \mathrm{B} 2$ 
Table 1. Establishment and procedure of different treatment.

\begin{tabular}{|c|c|c|c|c|}
\hline Groups & UV-B radiation dose & light culture & $\begin{array}{c}\text { Enhanced } \\
\text { UV-B radiation }\end{array}$ & $\begin{array}{c}\text { Dark } \\
\text { culture }\end{array}$ \\
\hline CK & & $8 \mathrm{~h} / \mathrm{d}$ & & $16 \mathrm{~h} / \mathrm{d}$ \\
\hline $\mathrm{B}_{1}$ & $4.05 \mathrm{~kJ} \cdot \mathrm{m}^{-2} \cdot \mathrm{d}^{-1}$ & $8 \mathrm{~h} / \mathrm{d}$ & $8 \mathrm{~h} / \mathrm{d}$ & $16 \mathrm{~h} / \mathrm{d}$ \\
\hline $\mathrm{B}_{2}$ & $10.08 \mathrm{~kJ} \cdot \mathrm{m}^{-2} \cdot \mathrm{d}^{-1}$ & $8 \mathrm{~h} / \mathrm{d}$ & $8 \mathrm{~h} / \mathrm{d}$ & $16 \mathrm{~h} / \mathrm{d}$ \\
\hline $\mathrm{B}_{3}$ & $17.05 \mathrm{~kJ} \cdot \mathrm{m}^{-2} \cdot \mathrm{d}^{-1}$ & $8 \mathrm{~h} / \mathrm{d}$ & $8 \mathrm{~h} / \mathrm{d}$ & $16 \mathrm{~h} / \mathrm{d}$ \\
\hline $\mathrm{B}_{4}$ & $23.02 \mathrm{~kJ} \cdot \mathrm{m}^{-2} \cdot \mathrm{d}^{-1}$ & $8 \mathrm{~h} / \mathrm{d}$ & $8 \mathrm{~h} / \mathrm{d}$ & $16 \mathrm{~h} / \mathrm{d}$ \\
\hline
\end{tabular}

group: $10.08 \mathrm{~kJ} \cdot \mathrm{m}^{-2} \cdot \mathrm{d}^{-1}$; $\mathrm{B}_{3}$ group: $17.05 \mathrm{~kJ} \cdot \mathrm{m}^{-2} \cdot \mathrm{d}^{-1} ; \mathrm{B}_{4}$ group: $23.02 \mathrm{~kJ} \cdot \mathrm{m}^{-2} \cdot \mathrm{d}^{-1}$.

\subsection{Root Tip Cells Immunolabeling}

The root tips of two-day-old wheat seedlings were cut into $2 \mathrm{~mm}$ fragments and used for imunolabeling. Root tips of wheat were fixed with paraformaldehyde for $1 \mathrm{~h}$, and cellulase and pectinase were used for enzymolysis to take out the cell wall for $2 \mathrm{~h}$. Then, the root tip were used polyglutamic acid to fix for the root tip did not move. Following, then the root tip cells were incubated at room temperature with DAPI (DAPI was used to stain the cell nuclei (blue) at a concentration diluted 700 folds). Then, root-tip cells should be observed with confocal laser scanning microscopy (CLSM).

\section{Results}

\subsection{The Effects That the Increase of Enhanced UV-B Radiation Dose on Wheat Root Tip Growth and Development}

By observe the wheat root tip in control group (CK), enhanced UV-B radiation first group $\left(\mathrm{B}_{1}\right)$, enhanced UV-B radiation second group $\left(\mathrm{B}_{2}\right)$, enhanced UV-B radiation third group enhanced UV-B radiation third group $\left(\mathrm{B}_{3}\right)$, enhanced UV-B radiation fourth group $\left(\mathrm{B}_{4}\right)$ (in Figure 1), we drew the following conclusion: compared with control group (CK), we observed that low doses of enhanced UV-B group $\left(\mathrm{B}_{1}\right)$, root tip became longer and more straight, and root tip meristematic zones also significantly became longer in $B_{1}$ group. With the increase of enhanced UV-B radiation dose, we observed the wheat root tip became shorter and more bent. At the same time, we observed root tip meristematic zones are also becoming shorter, when the radiation dose reaches a certain value, we can hardly observe meristematic zones with the naked eye. We infer from the above conclusion that low doses of UV-B can promote the growth and development of wheat root and root tip meristematic area, but a high dose of enhanced UV-B, and can inhibit the wheat root tip and the growth and development of root tip meristematic zone.

\subsection{Enhanced UV-B Radiation Effects on Mitotic Rate}

Observation of $\mathrm{CK}$ group and $\mathrm{B}_{1}, \mathrm{~B}_{2}, \mathrm{~B}_{3}$, $\mathrm{B}_{4}$ group of wheat root tip cells, and statistical cells in mitosis phase, then we got the results of Table 2. Low doses of enhanced UV-B group $\left(B_{1}\right)$ group of mitotic cell count compared with control group (CK) increase for $115.84 \%$ that low doses of UV-B light can obviously promote the wheat root tip cell divide. However, with the increase of UV-B radiation dose, treatment group of mitotic cells was obviously reduce when comparing with the control group (CK). Even the high doses of enhanced UV-B group $\left(\mathrm{B}_{4}\right)$ group of mitotic cell count compared with control group (CK) decrease for $25.77 \%$ that high doses of UV-B light can obviously inhibit the wheat root tip cell divide.

\subsection{Enhanced UV-B Radiation on the Rate of the Chromosome Aberration of Wheat Root Tip Cells}

For example, the Table 3 lists the control group (CK) with different enhanced UV-B treatment group aberration rate and relative rate aberration is obviously different. Illustrate the UV-B treatment can cause obvious chromosome and cell aberration. Control group (CK) aberration rate is $0.599 \%$, however, Low doses of $\mathrm{B}_{1}$ group distor- 


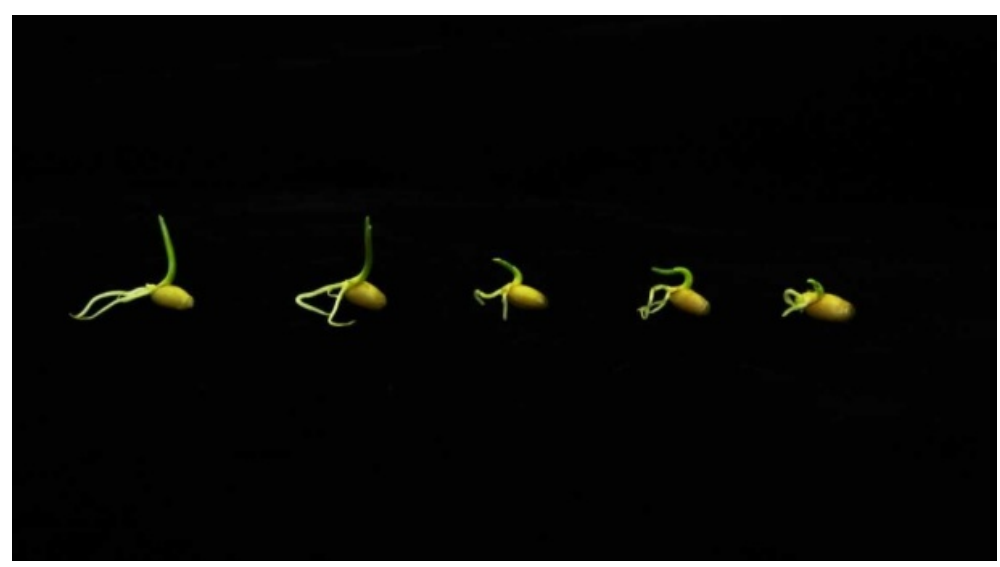

Figure 1. different UV-B groups of wheat root growth: from left to right, followed by CK, B1, B2, B3, B4 group.

Table 2. Effects of the UV-B radiation on the rate of the mitosis of the wheat.

\begin{tabular}{|c|c|c|c|c|c|c|c|}
\hline \multirow{2}{*}{ Groups } & \multirow{2}{*}{$\begin{array}{c}\text { Total of } \\
\text { observing cells }\end{array}$} & \multirow{2}{*}{$\begin{array}{c}\text { Total of } \\
\text { dividing } \\
\text { cells }\end{array}$} & \multicolumn{3}{|c|}{$\begin{array}{c}\text { Percentage of } \\
\text { dividing cells (\%) }\end{array}$} & \multirow{2}{*}{$\begin{array}{c}\text { Arithmetic } \\
\text { mean } \pm \text { range } \\
\mathrm{X} \pm \mathrm{SE}\end{array}$} & \multirow{2}{*}{$\begin{array}{c}\text { Rate of } \\
\text { Relativity } \\
\text { (\%) }\end{array}$} \\
\hline & & & No.1 & No.2 & No.3 & & \\
\hline CK & 20015 & 846 & 4.16 & 4.12 & 4.41 & $4.23 \pm 0.17$ & 100.00 \\
\hline $\mathrm{B}_{1}$ & 20023 & 982 & 4.92 & 4.78 & 5.00 & $4.90 \pm 0.11$ & 115.84 \\
\hline $\mathrm{B}_{2}$ & 20028 & 643 & 3.12 & 3.07 & 3.44 & $3.21 \pm 0.91$ & 75.84 \\
\hline $\mathrm{B}_{3}$ & 20033 & 451 & 2.29 & 2.13 & 2.33 & $2.25 \pm 0.10$ & 53.19 \\
\hline $\mathrm{B}_{4}$ & 20042 & 218 & 1.13 & 0.93 & 1.21 & $1.09 \pm 0.14$ & 25.77 \\
\hline
\end{tabular}

Table 3. Effects of UV-B radiation on the rate of the chromosome aberration of the wheat.

\begin{tabular}{|c|c|c|c|c|c|c|c|}
\hline \multirow{2}{*}{ Groups } & \multirow{2}{*}{$\begin{array}{c}\text { Total of } \\
\text { observing cells }\end{array}$} & \multirow{2}{*}{$\begin{array}{c}\text { Total of aberration } \\
\text { cells }\end{array}$} & \multicolumn{3}{|c|}{ Aberration percentage (\%) } & \multirow{2}{*}{$\begin{array}{c}\text { Arithmetic } \\
\text { mean } \pm \text { range } \\
X \pm S E\end{array}$} & \multirow{2}{*}{$\begin{array}{c}\text { Rate of relativity } \\
\text { (\%) }\end{array}$} \\
\hline & & & No.1. & No.2 & No.3 & & \\
\hline CK & 20025 & 120 & 0.596 & 0.587 & 0.603 & $0.599 \pm 0.008$ & 100 \\
\hline $\mathrm{B}_{1}$ & 20037 & 95 & 0.468 & 0.492 & 0.492 & $0.474 \pm 0.013$ & 79.1 \\
\hline $\mathrm{B}_{2}$ & 20013 & 782 & 3.89 & 4.02 & 4.02 & $3.91 \pm 0.10$ & 653 \\
\hline $\mathrm{B}_{3}$ & 20020 & 1020 & 5.03 & 5.23 & 5.23 & $5.10 \pm 0.13$ & 851 \\
\hline $\mathrm{B}_{4}$ & 20032 & 1842 & 9.30 & 9.20 & 9.42 & $9.20 \pm 0.21$ & 1536 \\
\hline
\end{tabular}

tion rate is only $0.474 \%$, it shows that the low doses of UV-B can promote the normal mitosis and reduce the chromosome aberration rate. But high doses of UV-B group contain $\mathrm{B}_{2}, \mathrm{~B}_{3}, \mathrm{~B}_{4}$ group of cellular aberration rate with 3.91\%, 5.10\%, 9.20\%. The research shows that high doses enhance UV-B inhibition normal distribution of mitosis and chromosome distribution.

\subsection{The Effects on Wheat Root Tip Cell Chromosome Aberration Types from the Enhanced UV-B Radiation Dose}

In the interphase of the cell cycle with enhanced UV-B radiation dose, in the nuclei of nucleoli number gradually increased, high dose of enhanced UV-B destroy the integrity of the nuclei, even in some appear "long round nuclei", "bean sprouts nucleus" (Figure 2). With the increase of UV-B radiation dose, mitotic most concentrated in the interphase. When the cell entered into the mitotic M phase, different UV-B treatment groups, comparing 
with control group (CK), show many types of chromosome aberration. They contain "dissociative chromosome", "Chromosome Bridge”, adhesion chromosome”, “multi-bundle divide”, "nuclear anomalies”. Different groups' aberration type and aberration rate in Table 4.

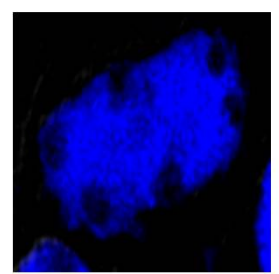

(e)

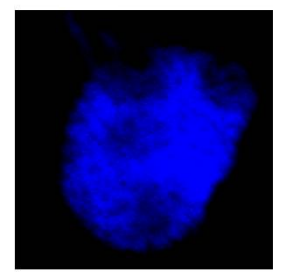

(i)

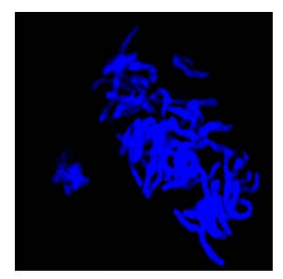

(m)

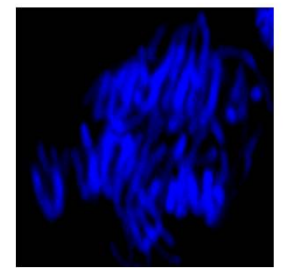

(b)

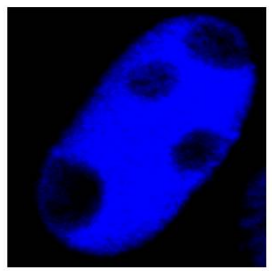

(f)

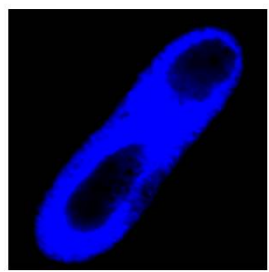

(j)

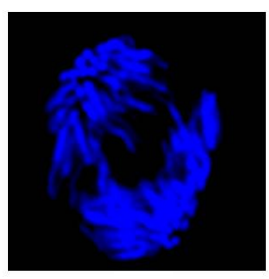

(n)

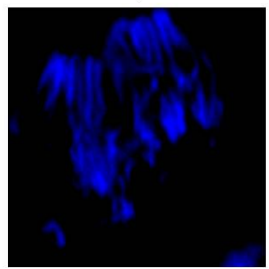

(c)

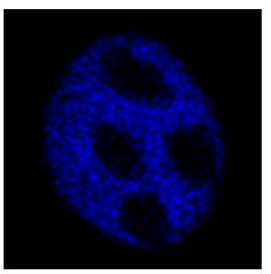

(g)

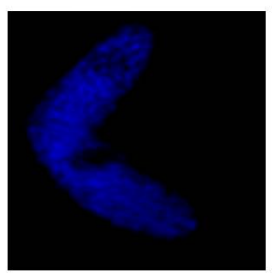

(k)

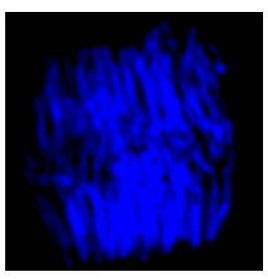

(o)

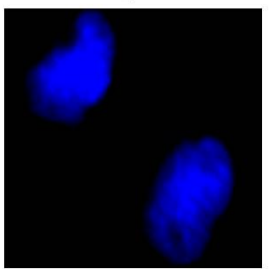

(d)

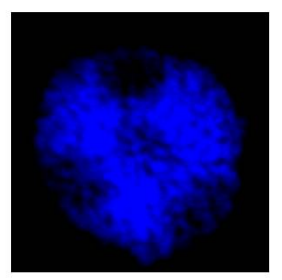

(h)

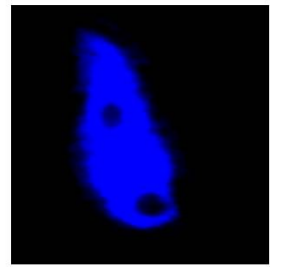

(I)

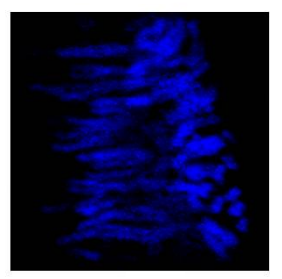

(p)

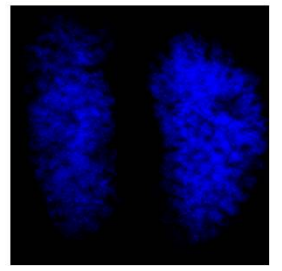

Figure 2. (a)-(c): multiple nucleoli nucle; (d)-(e): incomplete nuclei; (f): long round nuclei; (g)-(h): bean sprouts nucleus; (i): dissociative chromosome; (j): chromosome bridge; (k)-(l): adhesion chromosome; (m)-(n): multi-bundle divides; (o)-(p): nuclear anomalies.

Table 4. The type of the chromosome aberration of the wheat under the enhanced ultraviolet-B radiation.

\begin{tabular}{cccccc}
\hline Aberration type & CK aberration rate & $\mathrm{B}_{1}$ aberration rate & $\mathrm{B}_{2}$ aberration rate & $\mathrm{B}_{3}$ aberration rate & $\mathrm{B}_{4}$ aberration rate \\
\hline multiple nucleoli nucle & 0.22 & 0.17 & 1.58 & 2.36 & 4.13 \\
incomplete nuclei & 0.08 & 0.058 & 0.478 & 0.619 & 1.40 \\
long round nuclei & 0.14 & 0.127 & 0.31 & 0.497 & 1.03 \\
bean sprouts nucleus & 0.12 & 0.088 & 0.327 & 0.478 & 0.64 \\
dissociative chromosome & 0 & 0 & 0.185 & 0.327 & 0.478 \\
chromosome bridge & 0 & 0 & 0.063 & 0.166 & 0.33 \\
adhesion chromosome & 0.03 & 0.019 & 0.380 & 0.151 & 0.41 \\
multi-bundle divide & 0 & 0 & 0.409 & 0.31 & 0.424 \\
nuclear anomalies & 0 & 0 & 0.078 & 0.136 \\
\hline
\end{tabular}




\section{Discussion}

This study found that compared with control group (CK), low dose of UV-B irradiation $\left(\mathrm{B}_{1}\right)$ can make wheat root growth straighter and longer, with high doses of UV-B irradiation makes wheat root growth shorter and bender. On the basis of such front research, we made further exploration on whether the growth of wheat root tip has relationship with the mitosis of wheat root tip cell. Then, we found that compared with the control group (CK), the low doses of enhanced UV-B group $\left(B_{1}\right)$ treatment group mitosis frequency was obviously higher, and produce fewer aberration types, while the high dose of enhanced UV-B treatment groups mitosis frequency was significantly reduced, and produced a variety of aberration phenomenon, the observed consistent with wheat root growth, it shows that both have a certain correlation.

Low doses of enhanced UV-B can promote the growth of wheat root and promote cell division index. It might be the result of self-healing function of plant in adversity environment, then further produced some biological hormone and promoted the production of flavonoids, thus promoted the growth of plants. However, high doses of enhanced UV-B inhibited the growth of wheat root and cell mitosis, even when the radiation dose reaches a certain level, the wheat root tip can hardly grow in a normal way, and cell division index would drop significantly. This may be the result of high doses of UV-B that break down the plant self-protection system and further inhibit the action of the cell DNA replication transcription and protein synthesis.

Along with increasing enhanced UV-B radiation dose, the chromosome aberration rate is on the rise. The main reason of chromosome aberration phenomenon is that chromosomes are not synchronized movement. It speculated that UV-B radiation could make the spindle structure or function affected, leading to the spindle fiber imbalance on both sides of the centromere traction power, or chromosome acentric fracture cannot cause chromosome normal movement [20]. And UV-B radiation can make cell DNA base mutate, and form a pyrimidine dimer. Once the formation of dimmers is made in DNA, double chain of hydrogen bonds are damaged, and the normal DNA replication would not be performed. This could cause chromosome mutations occur during cell division [21].

In the metaphase and anaphase of mitosis, it produced a variety of the chromosome aberration types. There were produced lots of "dissociative chromosome", "Chromosome Bridge”, "adhesion chromosome”, and "multi-bundle divide". The cause of "dissociative chromosome" may be chromosome break without fusion, and may appear chromosome fragments, which formed the "dissociative chromosomes" [22]. The causes of "Chromosome Bridge” may be enhanced UV-B radiation, making chromosome break, then the two chromosomes sides are respectively healed, producing with double centromere chromosomes, cell division by two late centromere traction "chromosome bridges" will occur. "Adhesions chromosome" may have caused a similar process with Chromosome Bridge. Only more chromosomes' participation can eventually form "chromosomes adhesion". From the observation of "multi-bundle divide", we can see that there are focused beams of chromosomes poles distribution, rather than a multipolar distribution in multi-bundle divide cells. In "multi-bundle divide", each "bundle" of the number of chromosomes vast majority is less than normal cells, but they can't be meiosis. Because "multi-bundle divide" occurs in somatic cells rather than in the sex cells, in addition, between the "bundles" there is no cell walls and no formation haploid cells [23].

\section{Conclusion}

This paper mainly explores after different doses of the enhanced UV-B radiation treatment, the growth of wheat root tip cells were change with different doses of the enhanced UV-B radiation, and further use LCSM observation of wheat root tip cell mitosis, we found some abnormal mitosis phenomena. And with the enhanced of the UV-B dose change, abnormal mitosis shows consistent with the abnormal growth of wheat root. This illustrates wheat root tip cell mitotic division and wheat root tip growth has certain correlation, but the specific contact is to be further researched, and the enhanced UV-B radiation of high dose treatment wheat, then, in anaphase of mitosis of wheat root tip cell, the mechanism of "multi-bundle division" is produced and need to be further explored.

\section{Acknowledgements}

The work was supported by the National Nature Science Foundation of China (no. 30671061) and the Natural Science of Shanxi Province (no. 20081101, 2014011028-5). 


\section{References}

[1] Lantican, M.A., Dubin, H.J. and Morris, M.L. (2005) Impacts of International Wheat Breeding Research in the Developing World, 1988-2002. CIMMYT, Mexico.

[2] Zhao, J., Chen, H.Z. and Han, R. (2014) The Effects of He-Ne Laser and Enhanced Ultraviolet-B Radiation on PCNA in Wheat Seedlings. VEGETOS, 27, 17-24.

[3] Jansen, M.A.K., Gaba, V. and Greenberg, B.M. (1998) Higher Plants and UV-B Radiation Balancing Damage, Repair and Acclimation. Trends in Plant Science, 3, 131-135. http://dx.doi.org/10.1016/S1360-1385(98)01215-1

[4] Jenkins, G.I. (2009) Signal Transduction in Responses to UV-B Radiation. Annual Review of Plant Biology, 60, 407431. http://dx.doi.org/10.1146/annurev.arplant.59.032607.092953

[5] Taalas, P., Amanatidis, G.T. and Heikkilä, A. (2000) European Conference on Atmospheric UV Radiation: Overview. Journal of Geophysical Research: Atmospheres, 105, 4777-4785. http://dx.doi.org/10.1029/1999JD901181

[6] Chen, H.Z. and Han, R. (2014) He-Ne Laser Treatment Improves the Photosynthetic Efficiency of Wheat Exposed to Enhanced UV-B Radiation. Laser Physics, 24, 10-17. http://dx.doi.org/10.1088/1054-660X/24/10/105602

[7] Schmidt, E.C., Nunes, B.G., Maraschin, M. and Bouzon, Z.L. (2010) Effect of Ultraviolet-B Radiation on Growth, Photosynthetic Pigments, and Cell Biology of Kappaphycus alvarezii (Rhodophyta, Gigartinales) Macroalgae Brown Strain. Photosynthetica, 48, 161-172. http://dx.doi.org/10.1007/s11099-010-0022-7

[8] Chen, H.Z. and Han, R. (2015) F-Actin Participates in The Process of the Partition-Bundle Division. Russian Journal of Plant Physiology, 62, 187-194. http://dx.doi.org/10.1134/S102144371502003X

[9] Dante, R.A., Larkins, B.A. and Sabelli P.A. (2014) Cell Cycle Control and Seed Development. Frontiers in Plant science, 5, 493. http://dx.doi.org/10.3389/fpls.2014.00493

[10] Pablo, B.V., Yang, X. Wang, H.J., Chien, T.J. Chuang, M.H., Christopher A.M. and Guang, Y. J. (2013) Arabidopsis Chromosome Transmission Fidelity 7 (AtCTF7/ECO1) Is Required for DNA Repair, Mitosis and Meiosis. Plant Journal, 75, 927-940. http://dx.doi.org/10.1111/tpj.12261

[11] Diaz-Martinez, L.A. and Clarke, D.J. (2009) Chromosome Cohesion and the Spindle Checkpoint. Cell Cycle, 8, 27332740. http://dx.doi.org/10.4161/cc.8.17.9403

[12] Zheng, Y.F., Yang, Z.M. and Yan, J.Y. (1996) Biological Response of Crops on Enhanced Solar Ultraviolet Radiation and Its Estimation. Chinese Journal of Applied Ecology, 7, 107-109.

[13] Yue, M., Li, Y. and Wang, X.L. (1998) Effects of Enhanced Ultraviolet-B Radiation on Plant Nutrients and Decomposition of Spring Wheat Under Fiele Condition. Environmental and Experimental Botany, 40, 187-196. http://dx.doi.org/10.1016/S0098-8472(98)00036-7

[14] Chen, T., Wang, X.L. (1999) Influence of Enhanced UV-B Radiation on $\mathrm{H}_{2} \mathrm{O}_{2}$ Metabolism in Wheat Leaves. Acta Botanica Boreali-Occidentalia Sinica, 19, 284-289.

[15] Wrighi, L.A. and Murphy, T.M. (1987) UV Radiation Stimulated Efflux of Rubidium from Cultured Tobacco Cell. Plant Physiology, 61, 434-436. http://dx.doi.org/10.1104/pp.61.3.434

[16] Kramer, G.F., Norman, H.A. and Krizck, D.T. (1991) Influence of UV-B Radiation on Polyamines Lipids Peroxidation and Membrane Lipids Peroxidation and Membrane Lipids in Cucumber. Photochemistry, 30, 210-218. http://dx.doi.org/10.1016/0031-9422(91)83595-C

[17] Wang, S.Y. and Wang, X.L. (1999) The Tradescantia Micronucleus Test on the Geno-Toxicity of UV-B Radiation. Mutation Research, 4, 151-153. http://dx.doi.org/10.1016/S0027-5107(99)00059-7

[18] Li, F.F., Chen, H.Z. and Han, R. (2015) The Effects of He-Ne Laser and Enhanced Ultraviolet-B Radiation on Proliferating-Cell Nuclear Antigen in Wheat Seedlings. American Journal of Plant Sciences, 6, 1206-1214. http://dx.doi.org/10.4236/ajps.2015.68124

[19] Han, R. (2002) Effects of the Enhanced UV-B Radiation on the Body Cell Mitosis of the Wheat. PhD Dissertation, College of Life Sciences, Northwest University, Xi'an.

[20] Han, R., Zheng, Y.F. and Wang, C.H. (2007) Effects of Enhanced UV-B Radiation on the Growth of Aerial Parts and Root of Maize. Ecology and Environment, 2, 323-326.

[21] Barnes, P.W., Flint, S.D and Caldwell, M.M. (1990) Morphological Responses of Crop and Weel Species of Different Growth forms to UV-B Radiation. American Journal of Botany, 77, 1354-1360. http://dx.doi.org/10.2307/2444596

[22] Gao, L.M., Li, Y.F. and Han, R. (2010) Studies on Effect Metablisms of Enhanced UV-B Radiation on the Wheat Cell Abnormal Motisis. Acta Laser Biology Sinica, 19, 158-164.

[23] Han, R., Wang, X. L. and Yue, M. (2002) Enhanced UV-B Radiation Effects on Wheat Somatic Cell Division. Acta Genetica Sinica, 29, 537-541. 